\title{
Inventory of Large Mammal Species in the Ilgaz Mountains (Cankiri): A Major Ecological Corridor in Anatolia
}

\author{
Burak Akbaba1 ${ }^{\text {(D) }}$ Safak Bulut ${ }^{2}$ (D) \\ ${ }^{1}$ Hacettepe University, Department of Biology, Ankara, Turkey \\ ${ }^{2}$ Hitit University, Department of Molecular Biology and Genetics, Corum, Turkey
}

\section{ABSTRACT}

In:

$\mathrm{n}$ order to understand the processes engendered by different faunal elements in natural systems, and to plan how such systems should be managed and conserved, it is essential to start by determining the presence of those faunal elements, even large mammals. The entire range of North Anatolian Mountains provides suitable sheltering and feeding habitats for large mammals. The region stretching between Köroğlu Mountains (west) and Ilgaz Mountains (east) is one of the most important Anatolia's wildlife corridors. We located and identified the species of large mammals in the Ilgaz Mountains, as well as specific habitats used by them. Field studies carried out in this region during April-August 2017 resulted in 180 records of nine different species of large mammals: Lepus europaeus, Ursus arctos, Canis lupus, Vulpes vulpes, Lynx lynx, Meles meles, Sus scrofa, Cervus elaphus and Capreolus capreolus. To obtain those records took 621 days of studying with camera traps. Among those species, European hare was the most frequently recorded herbivore (101), and brown bear was the most frequently recorded carnivore (19). Both hare and roe deer displayed clustered distribution patterns in the region. The analysis of our records showed that lynx, boar, and fox were strictly nocturnal; whereas hare and wolf were predominantly nocturnal. We also obtained records of the cubs of many large mammal species (bear, lynx, boar, red deer, roe deer) although we did not encounter any large mammal nests during the study.

Keywords:

Mammal, Camera trap, Çankırı, Ilgaz, Anatolia.

\section{INTRODUCTION}

M ammal species with a weight of over one kilogram are known as large mammals [1]. In most ecosystems, species of large mammals living on land play prominent roles. Among these, large herbivores act as considerable modifiers of primary production, as well as nutrient cycles and soil properties, and even regimes of wildfires and bushfires [2]. Likewise, large carnivores play a major part in shaping the ecosystems they live in, by directly and indirectly effecting the species they prey on $[3,4]$. Home range sizes of large mammal species are relatively bigger than those of other vertebrates, and thus they require large, uninterrupted ecosystems for feeding and breeding [5]. They are also known to be very sensitive to disturbance, and show considerable intolerance against it [6]. In Anatolia, many of the ecosystems that large mammals may find favourable have either become fragmented, or they are completely destroyed as a result of human activities - a serious threat to the continuity of large mammal populations. Identifying the presence of different species in a given area and determining the habitats preferred by large mammals were the two key precautions in investigating the effects of habitat fragmentation and producing alternative solutions for the conservation of species [7].

As pointed out by Can and Togan [8], there was considerable lack of information on large mammal species living in Turkey, and there were no reliable systematic field surveys for most of them. This statement still remained valid for the majority of large mammal species in 2017. Therefore, it is clearly necessary to conduct more studies on large mammal in different parts of Anatolia for the purpose of protecting their habitats and the species themselves.

North Anatolian Mountains start with Köroğlu Mountains in the west and continue with Ilgaz Mountains towards the east, constituting a transition zone between the geographic regions of Central Anatolia 
and Western Black Sea, and thus is a very important location in terms of biological diversity. Forests extending from the Çamlıdere-Gerede border towards Çankırı province are thought to be of great importance as an ecological corridor. Ilgaz Mountains are a notable part of this corridor, as they still contain habitats that are not fragmented. The region also hosts an adequate vegetation cover, which provides shelter and food for large mammals, while also supporting the local and long-distance movements of these species between the Northwest and Northeast Anatolia. Preservation of such transition zones is crucial for the presence of large mammals in Anatolia.

We demonstrated the outcomes of our study that focused on determining the inventory of large mammal species in the Ilgaz Mountains. The number of records and the daily activity patterns of spotted species were all based on camera trap records. With these results, we aimed to provide scientific data and insight for future conservation efforts on the large mammals in the region, and to support feasible management plans involving the area.

\section{MATERIALS AND METHODS}

\section{Study Area}

We carried out our study in a part of Ilgaz Mountains in northern Turkey (coordinates: 41.016198 ${ }^{\circ}-32.916474^{\circ}$, $40.844273^{\circ}-33.100230^{\circ}, 41.048360^{\circ}-34.052563^{\circ}$, $41.138825^{\circ}-33.785055^{\circ}$, Fig. 1).

Ilgaz Mountains define a wide geography, stretching between and beyond the borders of Kastamonu and Çank1rı provinces. This study covered different parts around the Çankırı province. Ilgaz Mountains lie in the second row of North Anatolian Mountains, along the west-east plane. Il-

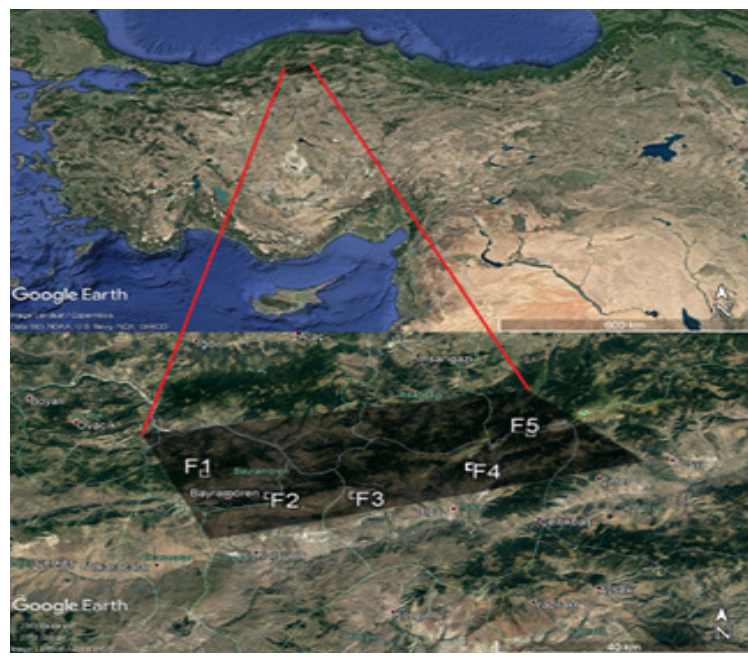

Figure 1. Location of the study area (Ilgaz Mountains, Çankırı Province, Turkey) - camera trap stations (F). gaz Mountains reach 2587 metres at the peak, and our study was carried out at 1000-2500 metres of altitude. Biogeographically, the mountains extend into two different floristic regions: the Mediterranean and the Euro-Siberian phytogeographical regions. The region has a dominant forest vegetation, which contains communities of Pinus sylvestris L., Pinus nigra subsp. pallasiana (Lamb.) Holmboe, and Abies nordmanniana subsp. equitrojani (Asc. \& Sint. ex Boiss.) Coode \& Cullen. Ilgaz Mountains form a transition zone between the geographic regions of Central Anatolia and Western Black Sea, therefore having a climate influenced by both regions' typical characteristics. The summers are dry and cool, with snowy and rainy winters. The study area (along the southern slopes of the mountains) is dominated by an atypical Mediterranean climate, with extreme colds and limited rainfall $[9,10]$.

A section within the study area (approx. 1088.61 ha 337.75 ha of which is within the borders of Çankırı province) was declared a "Ilgaz Dağı National Park" in 1976 [11].

\section{Camera Trapping}

In order to determine and identify the large mammal fauna, we carried out camera trap surveys between April 2017 and August 2017. We used of five cameras, all of which were passive infrared (Keepguard Wildlife Cameras, Keepway Industrial, Asia Co., Ltd). Based on interviews previously conducted with the locals living in the area, we targeted large mammal species belonging to the orders of Lagomorpha, Carnivora, and Cetartiodactyla: European hare (Lepus europaeus Pallas, 1778), brown bear (Ursus arctos L. 1758), wolf (Canis lupus L. 1758), golden jackal (Canis aureus L. 1758), red fox (Vulpes vulpes L. 1758), Eurasian lynx (Lynx lynx L. 1758), wild cat (Felis silvestris Schreber, 1777), European badger (Meles meles L. 1758), European pine marten (Martes martes L. 1758) and/or beech marten (Martes foina Erxleben, 1777), wild boar (Sus scrofa L. 1758), red deer (Cervus elaphus L. 1758), and roe deer (Capreolus capreolus L. 1758).

Trap spacing was known to have a significant effect in density studies [12]. The distances between camera traps have to be decided according to both the target species and the characteristics of the study area. In relative abundance studies that rely on presence-absence data, maximizing the possibility of photographing all species in the area is the main purpose, but camera spacing seemed to have little effect on the successful documentation of these species [13]. However, it is still important to adjust the distance between camera traps -the distances should be far apart enough to record an adequate number of individuals in the sampling area, but at the same time, close enough to avoid missing any individuals in the sampling area [14]. For our study, we 
decided to place the camera traps approximately $5-10 \mathrm{~km}$ apart in order to maximize the coverage area, but kept the distance between the traps at $<10 \mathrm{~km}$ in order to avoid missing species that have relatively small home ranges (e.g. marten species). Trap locations were fixed throughout the entire period of our study. Cameras were only replaced if one got stolen or broken for any reason.

One month prior to the beginning of our sampling efforts, we scouted the area for any possible clues indicating the presence of large mammal species (e.g. faeces, tracks). We placed the camera traps on paths and trails, where we detected and identified such clues. All cameras were positioned at 50-70 $\mathrm{cm}$ of height on average, and the focal range was set to 5-7 metres. All the cameras and sensors were protected with weather-resistant covers mounted on rigid vegetation. We visited the traps every month in order to get the captured visuals and to check if battery replacement was necessary. By using Garmin GPSMAP 60 CSX (Garmin International, Inc., Olathe, KS, USA), we recorded the geographic positions of all camera trap stations and plotted them (Fig. 1). The triggering mechanism for camera traps relied on sensors that can detect heat and/or motion within the range of a conical infrared beam. An approximate lag of 0.3 seconds was observed from the time the sensor detects an animal and the time the camera is triggered. Consecutive shots had a 10 second delay in between.

\section{Data Analysis}

We assumed that consecutive photographs of a specific species taken by the same camera trap in a relatively short period [within $1 \mathrm{hr} ; 15,16$ ] represented the same individual, keeping in mind that some species may linger around or in front of a camera for longer periods. Therefore, we filtered all such multiple visuals belonging to target species, and evaluated them as a single "record." Photographs displaying a group containing individuals of the same species were also evaluated as single records for the given species. The capture rates for species were calculated by considering the number of records taken in 100 camera trap days (CTD), and this value was called the relative capture frequency (RCF). These RCF values were then used in determining the distribution patterns (random, regular, or clustered) of all species targeted within the area of study. To demonstrate the significant variations in the number of records among different camera trap stations for a given species, we performed $\chi^{2}$ tests.

The number of records taken at different hours in a day was assumed to reflect the daily activity preferences of target species. To describe these activity patterns for all target species, we used the timestamps on the records. We then analysed these activity preferences by tabulating the number of records for all species in 2-h intervals. In order to come up with results that can be evaluated as statistically significant, we performed this analysis only for species with the adequate number of records [17]. The records were later classified into three different daily activity preference groups (diurnal, nocturnal, or crepuscular) depending on the capturing period. The species were assumed to be diurnal if the records were taken during 06:00-17:59, nocturnal if the records were taken during 18:00-05:59, and crepuscular if the records were taken during 04:00-07:59 or 16:00-19:59. We performed $\chi^{2}$ tests to determine the significant differences in the number of records belonging to particular daily activity preference groups for all our target species. The significance level was determined by using an $\alpha$ value of 0.05 .

All statistical analysis and graphs were made by STATISTICA (v. 8.0; StatSoft, Inc., Tulsa, OK, USA).

\section{RESULTS}

We distributed the observation effort among camera trap stations according to how many days each one worked for (CTDs); F1: 142 (23\%), F2: 120 (19\%), F3: 96 (16\%), F4: 121 (19\%), and F5: 142 (23\%). The total sampling effort of 621 CTDs yielded 311 independent camera trap records for further analysis, after filtering our photographs as described under the data analysis section. Among these 311 records, we found that $58 \%$ of the records (180 out of 311) belonged to the target species, whereas $42 \%$ (131 out of 311) were photographs of domestic animals, humans, small mammals, birds, and reptiles.

In the study area, we ended up capturing the photographs of 9 different species of large terrestrial mammals (see appendices for their photographs). Among our target species, the most frequently recorded was hare (101 times; 56.11\% of all the records belonging to all target species), followed by roe deer (19 times; 10.56\%) and bear (19 times; 10.56\%), red deer (12 times; 6.67\%) and lynx (12 times; 6.67\%), wolf (nine times; 5\%), boar (four times; 2.22\%), badger (twice; 1.11\%), and fox (twice; 1.11\%). Table 1 shows the RCF values for each species, and how many days it took a trap to capture that species in the study area (first capture day: FCD).

Table 2 showed the distribution of RCF values for each species among all camera trap stations during the entire study period. The comparison of these values among camera trap stations gave statistically significant differences for hare and roe deer $\left(\chi^{2}=134.20 ; \chi^{2}=37.05\right.$, respectively; $\mathrm{df}=4$; $\mathrm{p}<0.05)$, but the comparison for all other species proved to be statistically insignificant ( $p>0.05)$.

We determined a statistically significant difference in the number of records taken during three designated daily 
Table 1. Number of records, RCF values, and first capture days of target species.

\begin{tabular}{|c|c|c|c|c|c|}
\hline \multirow[b]{2}{*}{ Order } & \multicolumn{2}{|l|}{ Species } & \multirow[b]{2}{*}{ Number of Records } & \multirow[b]{2}{*}{$\mathrm{RCF}^{*}$} & \multirow[b]{2}{*}{$\mathrm{FCD}^{*}$} \\
\hline & English Name & Latin Name & & & \\
\hline Lagomorpha & European hare & Lepus europaeus Pallas, 1778 & 101 & 16.26 & 2 \\
\hline \multirow{5}{*}{ Carnivora } & Brown bear & Ursus arctos L. 1758 & 19 & 3.06 & 13 \\
\hline & Wolf & Canis lupus L. 1758 & 9 & 1.45 & 43 \\
\hline & Red fox & Vulpes vulpes (L. 1758) & 2 & 0.32 & 121 \\
\hline & Eurasian lynx & Lynx lynx (L. 1758) & 12 & 1.93 & 52 \\
\hline & Badger & Meles meles (L. 1758) & 2 & 0.32 & 38 \\
\hline \multirow{4}{*}{ Cetartiodactyla } & Wild boar & Sus scrofa L. 1758 & 4 & 0.64 & 30 \\
\hline & Red deer & Cervus elaphus L. 1758 & 12 & 1.93 & 18 \\
\hline & Roe deer & Capreolus capreolus (L. 1758) & 19 & 3.06 & 43 \\
\hline & Total & & 180 & 28.98 & \\
\hline
\end{tabular}

*RCF: Relative capture frequency, FCD: First capture day

activity preference periods for hare, lynx, wolf, boar, and fox $\left(\chi^{2}=108.59 ; 200.02 ; 107.43 ; 200.02 ; 200.02 ; \mathrm{df}=2 ; \mathrm{p}<0.05\right.$, respectively), and this was interpreted as an indication that these five species were nocturnal. Camera traps yielded an equal number of records during all periods for badger; and there was no statistically significant difference in number of records taken during each period for bear, red deer, and roe deer ( $p>0.05$, Table 3$)$.

We analysed the daily activity patterns of carnivorous large mammals that were recorded at least nine times. The results revealed that bear was active from 12:00 to 08:00, frequently between 22:00 and 04:00; that lynx preferred being active during 20:00-00:00 and from 02:00 to 04:00; and that wolf was active both from 20:00 to 02:00 and from 04:00 to 08:00 (Fig. 2).

Table 2. Distribution of RCF values for each species among all camera trap stations

\begin{tabular}{lllllll}
\hline \multirow{2}{*}{ Species } & \multicolumn{7}{c}{ Camera Trap Stations } & \\
\cline { 2 - 6 } & F1 & F2 & F3 & F4 & F5 & \\
\hline European hare & 0.70 & 9.17 & 66.67 & 19.00 & 1.41 & 16.26 \\
\hline Roe deer & 2.82 & 0.00 & 0.00 & 11.57 & 0.70 & 3.06 \\
\hline Brown bear & 2.11 & 1.67 & 2.08 & 7.44 & 2.11 & 3.06 \\
\hline Red deer & 1.41 & 0.83 & 4.16 & 1.65 & 2.11 & 1.93 \\
\hline Eurasian lynx & 1.41 & 3.33 & 5.20 & 0.83 & 0.00 & 1.93 \\
\hline Wolf & 0.70 & 5.00 & 1.04 & 0.00 & 0.70 & 1.45 \\
\hline Wild boar & 0.00 & 1.67 & 0.00 & 0.00 & 1.41 & 0.64 \\
\hline Badger & 0.00 & 0.00 & 1.04 & 0.83 & 0.00 & 0.32 \\
\hline Red fox & 0.00 & 0.83 & 0.00 & 0.00 & 0.70 & 0.32 \\
\hline Total & 9.15 & 22.50 & 80.21 & 41.32 & 9.15 & 28.98 \\
\hline
\end{tabular}

Daily activity patterns of herbivorous large mammals, on the other hand, were analysed for species that had a minimum of 10 records. These results revealed a consistent presence of roe deer and red deer during all time periods, showing no clear preference for a specific activity pattern; whereas hare was active from 20:00 to 08:00, frequently between 20:00 and 04:00 (Fig. 3).

Although we did not encounter any nests belonging to any of the large mammal species during our study, our camera traps captured photographs of the cubs of several target species (Fig. 4).

\section{DISCUSSION AND CONCLUSION}

We revealed by evaluating the camera trap data that the habitat provided suitable habitats for large mammals sin-

Table 3. Daily activity preferences of the target species.

\begin{tabular}{llll}
\hline \multirow{2}{*}{ Species } & \multicolumn{2}{l}{ Daily Activity Preference* } \\
\cline { 2 - 4 } & Nocturnal & Diurnal & $\begin{array}{l}\text { Crepu s - } \\
\text { cular }\end{array}$ \\
\hline European hare & 88.12 & 11.88 & 20.79 \\
\hline Roe deer & 42.11 & 57.89 & 52.63 \\
\hline Brown bear & 74.68 & 26.32 & 31.58 \\
\hline Red deer & 75.00 & 25.00 & 50.00 \\
\hline Eurasian lynx & 100.00 & 0.00 & 0.00 \\
\hline Wolf & 88.89 & 11.11 & 33.33 \\
\hline Wild boar & 100.00 & 0.00 & 0.00 \\
\hline Badger & 50.00 & 50.00 & 50.00 \\
\hline Red fox & 100.00 & 0.00 & 0.00 \\
\hline${ }^{*}$ Percentages (\%) for daily activity patterns & \\
\hline
\end{tabular}



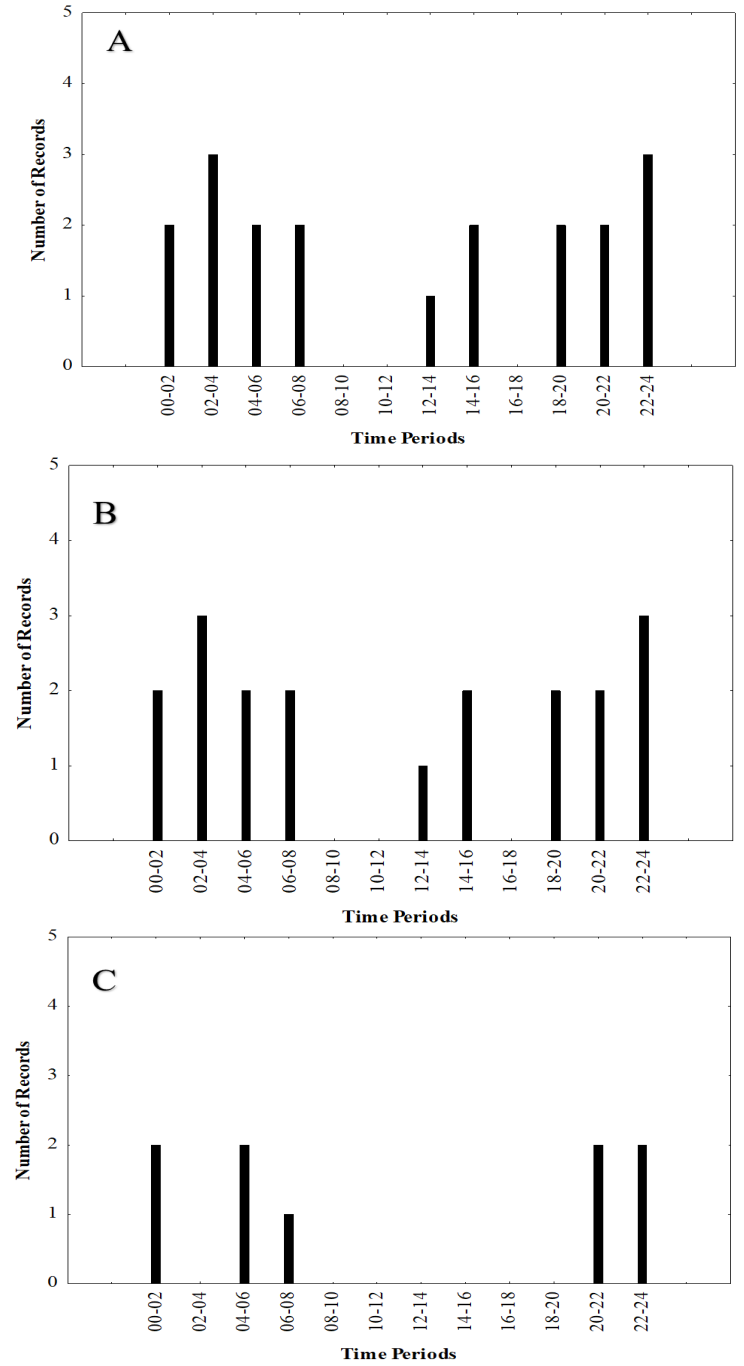

Figure 2. Daily activity patterns of carnivorous large mammals with minimum nine records: brown bear (A), Eurasian lynx (B), and wolf (C). The number of records from all five stations are shown with bars for each period.

ce we observed several large mammal species with high ecological requirements. This was the first time that a systematic camera trap study recorded the presence of hare, bear, wolf, fox, lynx, badger, boar, red deer, and roe deer in the Ilgaz Mountains. We determined that at least five of these species bred in the area, as indicated by the photographs of their cubs captured by our camera traps, further supporting the assumption about the area's potential importance.

Among the species we targeted were marten species, jackal, and wild cat, but we could not capture any of them. The questionnaire surveys conducted with the local people pointed out that no findings on the presence of jackals in the region. Accordingly, we did not encounter a single clue to indicate a jackal's presence during our field studies. Nevertheless, we identified footprints and faeces belonging to at least one marten species during our study, and encountered
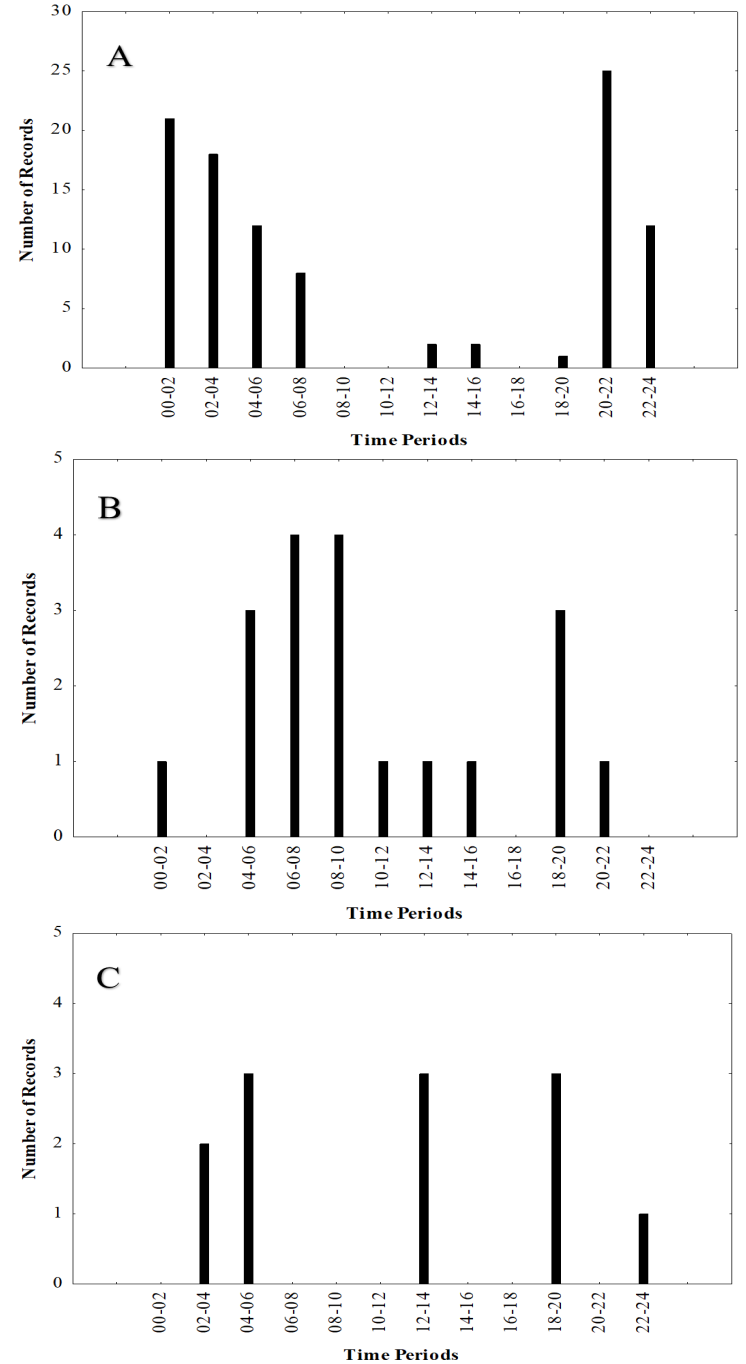

Figure 3. Daily activity patterns of herbivorous large mammals with minimum ten records: European hare (A), roe deer (B), and red deer (C). The number of records from all five stations are shown with bars for each period.

a wild cat in close proximity of the area. Photograph capturing rates may be affected by the animal size, as reported in recently conducted studies [13]. For our study, we placed the camera traps approximately $50 \mathrm{~cm}$ above the ground level in order to ensure capturing the species with large body sizes. This precaution, in return, might have led to missing the relatively smaller and rare species like marten and wild cat, both of which can move faster than other large mammals in the study area.

Hare was known to occur in almost all Turkey $[18,19]$. In this study, it was the most common species with 101 records, and it took only two days for our cameras to capture this species. Unexpectedly, boar and fox, which were known to be two other common species in Anatolia [18], were encounter with much lower frequency in the area. Fox was also the last captured large mammal species (after 121 days). The low density of human population in the study area, and 

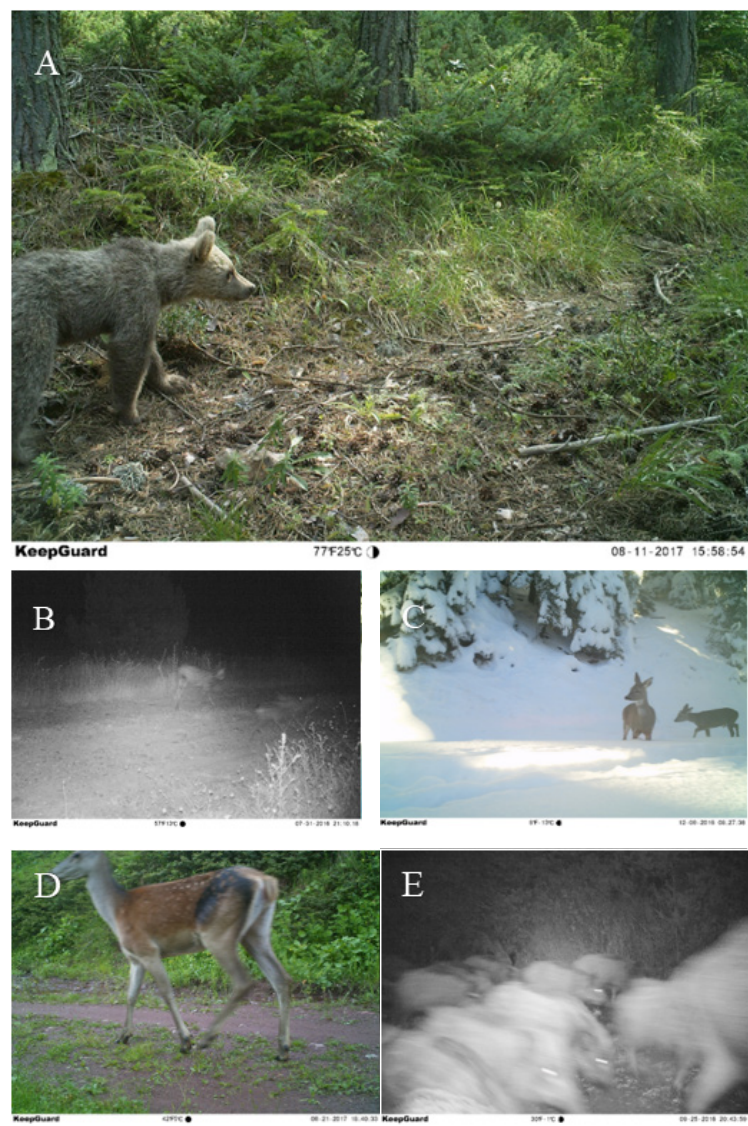

Figure 4. Cubs of target animals recorded during the study: brown bear (A), Eurasian lynx (B), roe deer (C), red deer (D), and wild boar (E).

therefore a significant lack of anthropogenic factors, might have encouraged sensitive species such as bear, lynx, and wolf to use the area more comfortably for feeding and breeding. Lynx preys on foxes [20], although their encounters did not always end with foxes being eaten [19]. Fox, by its generalist nature, can exploit resources efficiently in a variety of habitats, and could move to a different habitat in order to avoid predators that were relatively larger than itself [21]. We claimed that foxes dispersed to regions closer to human settlements located elsewhere, possibly due to the presence of bear, lynx, and wolf in the study area. The best possible explanation for the low RCF for boar was the predation by wolves [22]. Other reasons affecting the RCF values for boar might been the difference in climate (and accordingly, the availability of food), certain diseases, or hunting exploitation - although hunting was prohibited in the majority of the region.

Even though Tobler et al. [23] proposed that the abundance of a species might affect its RCF values, this correlation might not be useful for comparing the relative abundance of different species. This was due to numerous reasons including the relationship between the size of a species and the probability of a camera trap to capture this species, as well as differences in behaviour or home range size among species. Therefore, the RCF values we obtained during our study could not be used as actual indicators to make a deduction regarding the abundance of a species in comparison with others in the study area. The RCF values of species were used only for determining if they had random, regular, or clustered distribution in the study area. Roe deer and hare were evaluated to show clustered distributions in the region. Roe deer was concentrated particularly in Eksik village (Ilgaz district, F4 camera trap station), using this area especially in the post-breeding period. Hare was observed to intensely use the open lands inside the forest area between Kırışlar and Kayı villages (Ilgaz district, F3 camera trap station). The distributions of other target species were relatively homogeneous throughout Ilgaz Mountains, which extend approximately $60 \mathrm{~km}$ into Çankırı province.

We determined that wolves, lynxes, and hares showed similar activity preferences. The majority of the activities of these three species took place during the night; while bear, red deer, and roe deer showed activity in both daytime and twilight (fox, badger, and boar records were not analysed due to insufficient number of data). As we did not have a single capture for lynx during day hours, we could indicate that it was a strictly nocturnal species. The daily activity preference of lynx was indisputably related to its hunting behaviour [24]. As shown in recent studies, the primary prey of Anatolian populations of lynx was hare $[25,26]$. Thus, it makes sense that the activity periods preferred by lynx were in correlation with the nocturnal habits of its primary food source. Wolf was thought to have accommodated nocturnal behaviour in order to avoid encountering humans [19, 27], and the findings of our study also supported this.

The study area, along with the surrounding regions, was not subjected to heavy human activity. The region hosts very little human settlement. As a result, a good amount of high vegetation covers as well as abundant food might play a role in making the study area a favourable habitat for this cryptic species -indicators for the area's ecological significance. Our results provided scientific data and insight for future conservation efforts and management studies concerning the large mammal species in Ilgaz Mountains. Noteworthy records of large mammal species from the study area signified both the importance of our study, and the necessity of better management plans to ensure efficient protection of the region and the species it hosts.

\section{ACKNOWLEDGEMENT}

Camera traps and legal permissions were provided by The Ministry of Agriculture and Forestry, General Directorate of Nature Protection and National Parks (Turkey), and Çankırı Provincial Directorate of Nature Protection and National Parks. We are grateful to DOKAY 
Environmental Consultancy Company for providing the necessary support to realize this study, as well as our colleagues Dr. Tarkan Yorulmaz and Dr. Barış Özüdoğru for their assistance in the field. This study was supported by Hacettepe University's Scientific Research Projects Coordination Unit (Project Number: FHD-2017-13111).

\section{References}

1. Chiarello AG. Density and population size of mammals in remnants of Brazilian Atlantic Forest. Conservation Biology 14, no. 6 (2000) 1649-1657.

2. Gordon IJ. Restoring the functions of grazed ecosystems, in: Danell K, Bergström R, Duncan P, Pastor J (Eds.). Large herbivore ecology, ecosystem dynamics and conservation, Cambridge University Press, New York, pp. 449-467, 2006.

3. Sinclair ARE, Mduma S, Brashares JS. Patterns of predation in a diverse predator - prey system. Nature 425 (2003) 288-290.

4. Dalerum F, Somers MJ, Kunkel KE, Cameron EZ. The potential for large carnivores to act as biodiversity surrogates in southern Africa Biodiversity and Conservation 17, no. 12 (2008) 2939-2949.

5. Rocha EC, Brito D, Silva PM, Silva J, Bernardo PVS, Leandro J Effects of habitat fragmentation on the persistence of medium and large mammal species in the Brazilian Savanna of Goiás State. Biota Neotropica 18, no. 3 (2018) e20170483.

6. Cheynea SM, Sastramidjaja WJ, Muhalir, Rayadin Y, Macdonald DW. Mammalian communities as indicators of disturbance across Indonesian Borneo. Global Ecology and Conservation 7 (2016) 157-173.

7. Andrade-Núñez MJ, Mitchell Aide T. Effects of habitat and landscape characteristics on medium and large mammal species richness and composition in northern Uruguay. Zoologia 27, no. 6 (2010) 909-917.

8. Can ÖE, Togan I. Camera trapping of large mammals in Yenice Forest, Turkey: local information versus camera traps. Oryx 43, no. 3 (2009) 427-430.

9. Akman Y, Yurdakulol Y, Demirörs M. The vegetation of the Ilgaz Mountains. Ecologia Mediterranea IX, no. 2 (1983) 137-165.

10. Akman Y. İklim ve Biyoiklim, Palma Yayın Dağıtım, Ankara, 1990.

11. T.C. Çankırı Valiliği Çevre ve Şehircilik İl Müdürlüğü. Çankırı İli 2016 Yılı Çevre Durum Raporu, Çankırı, 2017.

12. Dillon A, Kelly MJ. Ocelot (Leopardus pardalis) in Belize: the impact of trap spacing and distance moved on density estimates. Oryx 41, no. 4 (2007) 469-477.

13. Kelly MJ. Design, evaluate, and refine: camera trap studies for elusive species. Animal Conservation 11 (2008) 182-184.

14. Meek PD, Ballard G, Claridge A, Kays R, Moseby K, O’Brien T. Recommended guiding principles for reporting on camera trapping research. Biodiversity and Conservation 23, no. 9 (2014) 2321-2343.

15. Bowkett AE, Rovero F, Marshall AR. The use of camera trap data to model habitat use by antelope species in the Udzungwa Mountain forests, Tanzania. African Journal of Ecology 46, no. 4 (2007) 479487.

16. Rovero F, Marshall AR. Camera trapping photographic rate as an index of density in forest ungulates. Journal of Applied Ecology 46 no. 5 (2009) 1011-1017.

17. Sanderson JG. Camera phototrapping monitoring protocol, The Tropical Ecology, Assessment and Monitoring (TEAM) Initiative, The Center for Applied Biodiversity Science, Conservation International, Washington, DC, pp. 18, 2004.

18. Demirsoy A. Türkiye Omurgalıları: Memeliler, Çevre Bakanlığı,

Çevre Koruma Genel Müdürlüğü, Meteksan A.Ş., Ankara, pp. 292, 1996.

19. Aulagnier S, Haffner F, Mitchell-Jones AJ, Moutou F, Zima J. Mammals of Europe, North Africa and the Middle East, Delachaux et Niestle SA, Paris, pp. 272, 2008.

20. Jobin A, Molinari P, Breitenmoser U. Prey spectrum, prey preference and consumption rates of Eurasian lynx in the Swiss Jura Mountains. Acta Theriologica 45, no. 2 (2000) 243-252.

21. Fedriani JM, Palomares F, Delibes M. Niche relations among three sympatric Mediterranean carnivores. Oecologia 121, no.1 (1999) $138-148$.

22. Jedrzejewska W, Jedrzejewska B, Okarma H, Schmidt K, Zub K, Musiani M. Prey selection and predation by wolves in Białowieza Primeval Forest, Poland. Journal of Mammalogy 81, no.1 (2000) 197-212.

23. Tobler MW, Carrillo-Percastegui SE, Leite Pitman R, Mares R, Powell G. An evaluation of camera traps for inventorying large and medium sized terrestrial rainforest mammals. Animal Conservation 11, no. 3 (2008) 169-178.

24. Jedrzejewski W, Schmidt K, Milkowski L, Jedrzejewska B, Okarma H. Foraging by lynx and its role in ungulate mortality: the local (Bialowieza Forest) and the Palearctic viewpoints. Acta Theriologica 38, no. 4 (1993) 385-403.

25. Mengüllüoğlu D, Ambarlı H, Berger A, Hofer H. Foraging ecology of Eurasian lynx populations in southwest Asia: Conservation implications for a diet specialist. Ecology and Evolution 8, no. 6 (2018) 9451-9463.

26. Soyumert A, Ertürk A, Tavşanoğlu Ç. The importance of lagomorphs for the Eurasian lynx in Western Asia: Results from a large scale camera-trapping survey in Turkey. Mammalian Biology 95 (2019) 18-25.

27. Theuerkauf J, Jedrzejewski W, Schmidt K, Okarma H, Ruczynski I, Sniezko S, Gula R. Daily patterns and duration of wolf activity in the Białowieza Forest, Poland. Journal of Mammalogy 84, no.1 (2003) 243-253.

\section{APPENDIX}

Record samples of large mammal species captured during the study: 1. Ursus arctos, 2. Canis lupus, 3a-3b. Lynx lynx, 4. Vulpes vulpes, 5. Meles meles, 6. Capreolus capreolus, 7. Cervus elaphus, 8. Sus scrofa, 9. Lepus europaeus.
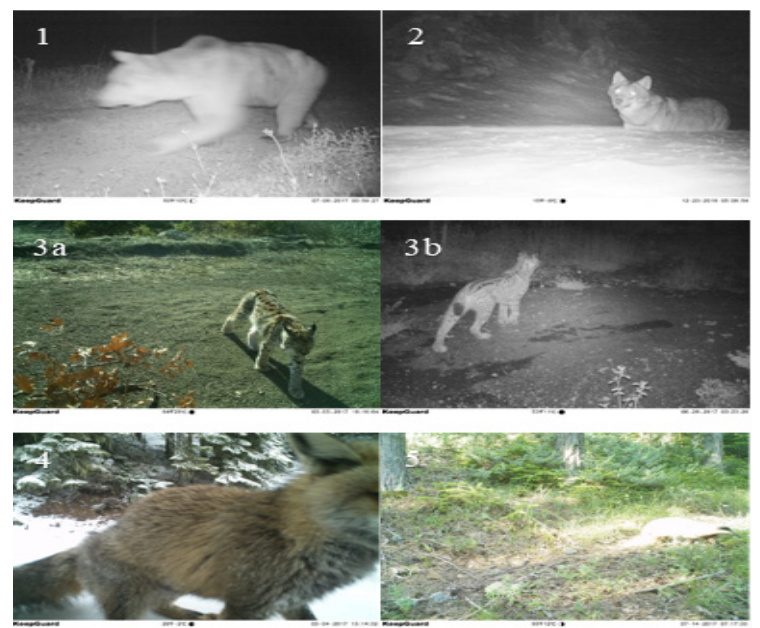

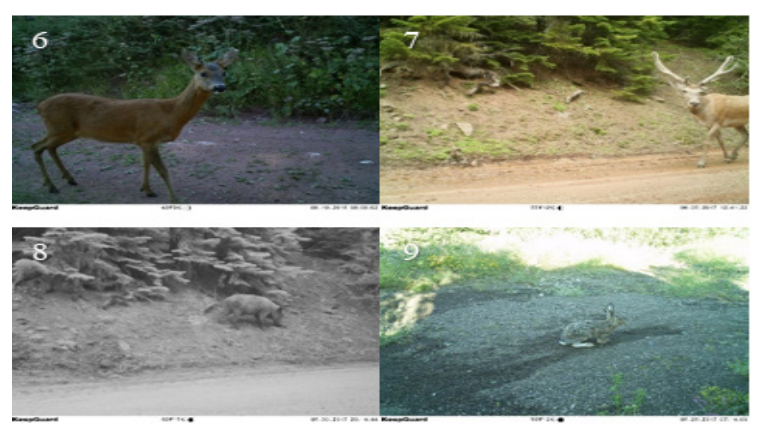

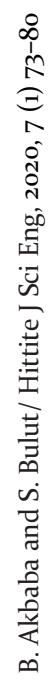

